\title{
CURRICULUM IN CARDIOLOGY
}

\section{PTCA of chronically occluded coronary arteries}

\author{
GertJan Laarman, MD, Sylvain Planté, MD, and Pim J. de Feyter, MD. \\ Rotterdam-Dijkzigt, The Netherlands
}

The progression of a coronary artery stenosis to total occlusion does not necessarily imply complete myocardial necrosis of the entire flow-dependent region of the vessel involved. ${ }^{1}$ Various degrees of perfusion can be maintained by a collateral circulation, so that the area of necrosis can be limited in size or infarction can even be prevented. During increased demand for myocardial oxygen the collateral blood flow may become insufficient, and symptoms of myocardial ischemia may arise. Signs of viable myocardial tissue are: angina pectoris in the absence of other significant coronary artery lesions, absence of $Q$ waves on the electrocardiogram, the preservation of left ventricular wall motion as shown by angiographic or echocardiographic techniques, and redistribution on thallium 201 scintigraphy. ${ }^{2,3}$ Angina pectoris (even unstable angina pectoris) may persist in spite of an optimal antiischemic drug regimen.

Percutaneous recanalization, followed by balloon dilatation, appears to be an attractive approach, since coronary bypass graft surgery, although a safe procedure, is now generally not considered to be the best treatment for single-vessel coronary artery disease. Percutaneous transluminal coronary angioplasty (PTCA) of chronically occluded coronary arteries, first described in $1982,4,5$ comprises approximately $10 \%$ of the total number of PTCA procedures. $^{2,6-9}$ This article reviews the factors that determine the initial success of angioplasty of chronic total coronary artery occlusions, as well as the clinical and angiographic follow-ups. A decision scheme for the approach to treatment of the patient with a chronic total occlusion is presented, and guidelines for the PTCA procedure are proposed. New tech-

From the Catheterization Laboratory, Thoraxcenter, University Hospital Rotterdam-Dijkzigt, The Netherlands.

Reprint requests: G. J. Laarman, MD, Catheterization Laboratory, Thoraxcenter, University Hospital Rotterdam-Dijkzigt, P.O. Box 1738, 3000 DR Rotterdam, The Netherlands.

4/1/19166 niques are described, which might be used if "older" techniques fail.

\section{PRIMARY SUCCESS OF PTCA OF CHRONICALLY OCCLUDED CORONARY ARTERIES}

The primary success rate of PTCA of chronically occluded vessels is mainly determined by the following factors: (1) the presence of functional or total occlusion, (2) the duration of the occlusion, (3) the length of the occluded segment, (4) the presence of collateral circulation, (5) the presence of a vessel stump, (6) the underlying pathology, and (7) the availability of new or additional technical devices.

Functional or total occlusion. Traditionally, coronary artery occlusion has been classified as either functional occlusion or total occlusion. Functional occlusion is defined as antegrade, faint and late opacification of the vessel segment beyond the occlusion with or without visible continuity of the artery. ${ }^{10}$ With the guide wire across the area of stenosis, complete occlusion commonly occurs. Total occlusion is defined as the absence of antegrade filling distal to the occlusion. In some cases, distal filling can be demonstrated through collaterals that originate proximally from the area of stenosis or from other vessels. Generally, the primary success rate of dilatation in the case of a functional occlusion is higher than that in the case of a total occlusion (Table I) ${ }^{6,7,10-13}$

Duration of the occlusion. The second most important determinant of primary success of PTCA of occluded vessels is the duration of the occlusion because the duration determines the consistency of the lesion. Occlusions of short duration often consist solely of fresh thrombus, whereas in later stages organization and calcification occur. It is often difficult to estimate the duration of the occlusion. The medical history (abrupt changes of symptoms), a sustained myocardial infarction, and the time of the diagnostic coronary angiogram are often helpful in making an approximation of the duration of the oc- 
Table I. Functional and total occlusion and initial success of PTCA

\begin{tabular}{|c|c|c|c|c|}
\hline \multirow[b]{2}{*}{ Authors (year) } & \multicolumn{2}{|c|}{ Total occlusion } & \multicolumn{2}{|c|}{ Functional occlusion } \\
\hline & Patients & Success & Patients & Success \\
\hline Dervan et al (1983). ${ }^{10}$ & 4 & $3(75 \%)$ & 9 & $4(44 \%)$ \\
\hline Kereiakes et al. $(1985)^{6}$ & 68 & $34(50 \%)$ & 8 & $6(75 \%)$ \\
\hline Geuskens et al. $(1986)^{7}$ & 51 & $24(47 \%)$ & 29 & $22(76 \%)$ \\
\hline DiSciascio et al. $(1986)^{11}$ & 23 & $13(57 \%)$ & 23 & $16(70 \%)$ \\
\hline Melchior et al. $(1987)^{12}$ & 100 & $56(56 \%)$ & - & $-(-)$ \\
\hline Safian et al. $(1988)^{13}$ & 169 & $86(51 \%)$ & 102 & $81(79 \%)$ \\
\hline Totals & $\frac{x+0}{415}$ & $216(52 \%)$ & $\frac{171}{171}$ & $129(75 \%)$ \\
\hline
\end{tabular}

Table II. Duration occlusion and success of PTCA

\begin{tabular}{|c|c|c|c|}
\hline Authors (year) & $\begin{array}{c}\text { Duration } \\
\text { of occlusion }\end{array}$ & Patients & Success \\
\hline \multirow[t]{2}{*}{ Holmes et al. $(1984)^{8}$} & $\leq 12$ weeks\# & 19 & $13(68 \%)$ \\
\hline & $>12$ weeks \# & $\mathbf{5}$ & $0(0 \%)$ \\
\hline \multirow[t]{2}{*}{ Kereiakes et al. $(1985)^{6}$} & $<20$ weeks\# & 55 & $33(67 \%)$ \\
\hline & $\geq 20$ weeks\# & 17 & $3(18 \%)$ \\
\hline \multirow[t]{4}{*}{ Geuskens et al. (1986) ${ }^{7}$} & $\leq 8$ weeks* & 18 & $16(89 \%)$ \\
\hline & $>8$ weeks* & 11 & $6(55 \%)$ \\
\hline & $\leq 8$ weeks\# & 29 & $16(55 \%)$ \\
\hline & $>8$ weeks\# & 22 & $8(36 \%)$ \\
\hline \multirow[t]{3}{*}{ DiSciascio et al. $(1986)^{11}$} & $<2$ weeks $\dagger$ & 19 & $14(74 \%)$ \\
\hline & $2-4$ weeks $\dagger$ & 9 & $6(67 \%)$ \\
\hline & $>4$ weeks $\dagger$ & 18 & $9(50 \%)$ \\
\hline \multirow[t]{3}{*}{ Melchior et al. $(1987)^{12}$} & $<1$ month\# & 52 & $36(69 \%)$ \\
\hline & 1-6 months\# & 38 & $19(50 \%)$ \\
\hline & $>6$ months\# & 9 & $1(11 \%)$ \\
\hline \multirow[t]{3}{*}{ Safian et al. $(1988)^{13}$} & $<1$ month $\dagger$ & 60 & $40(67 \%)$ \\
\hline & $1-6$ months $\dagger$ & 49 & $29(59 \%)$ \\
\hline & $>6$ months $\dagger$ & 60 & $33(55 \%)$ \\
\hline
\end{tabular}

\#Total occlusion.

*Functional occlusion.

$\dagger$ Total and functional occlusions.

clusion. Table II shows studies that deal with the duration aspect. ${ }^{6-8,11-13}$ It may be concluded that the primary success rate is substantially lower if the duration of the total occlusion is estimated to be more than 2 months as compared to an estimated duration of less than 2 months. The same holds true for the functional occlusion.

Length of the occluded segment. The length of the occluded segment can sometimes be assessed because of filling of the distal part of the vessel by adequate collateral circulation. This permits estimation of the length of the "missing" segment. Kereiakes et al. ${ }^{6}$ showed that the outcome of angioplasty was significantly influenced by the length of the nonvisualized segment. PTCA of occluded segments less than 1.5 cm in length was successful in $78 \%$ of the cases versus $42 \%$ in which the length of the occlusion was greater than $1.5 \mathrm{~cm}$.

Collateral circulation. The collateral circulation provides useful information on the length of the occlusion, opacification of the vessel distal to the occlusion that delineates the course of the vessel beyond the lesion ("roadmapping"), and possible distal abnormalities. ${ }^{9}$ Knowledge of the anatomy of the distal vessel may greatly facilitate crossing the area of stenosis with the wire, and it may reduce the risk of perforation of the vessel wall. The possible detrimental effects of collaterals on restenosis rate will also be discussed.

Other anatomic factors. The presence of a vessel stump beyond the last side branch (Fig. 1) may facilitate the procedure by giving direction to the guide wire and/or perfusion catheter. An occlusion in a straight vessel segment is another favorable factor. Great difficulty in crossing may arise if the occluded segment is located in a bend or if side branches arise from the most distal end of the stump.

Pathologic considerations. Although it may be unknown to the angiographer the underlying pathology of total occlusions may be different in individual cases (Fig. 2), and this may determine, to a great extent, the ultimate short- and long-term outcome ${ }^{14}$ : the "ideal" occlusion consists of a small, fresh, central thrombus surrounded by a firmer fibrocellular narrowing that permits easy passage of the wire within the vessel lumen. On the other hand, the lesion may consist of a rupture of complex plaque with a fibrous cap overlying soft atheromatous tissue or may even consist of massive fibromuscular tissue. In these situations the "path of least resistance" may run in the subintima, and attempted recanalization may be hazardous because of the considerable risk of vessel wall perforation (Fig. 3).

Availability and use of new devices and techniques. For successful perforation of the occlusion an optimal "pushability" of the guide wire and a good and stable fit of the guiding catheter in the ostium of the 


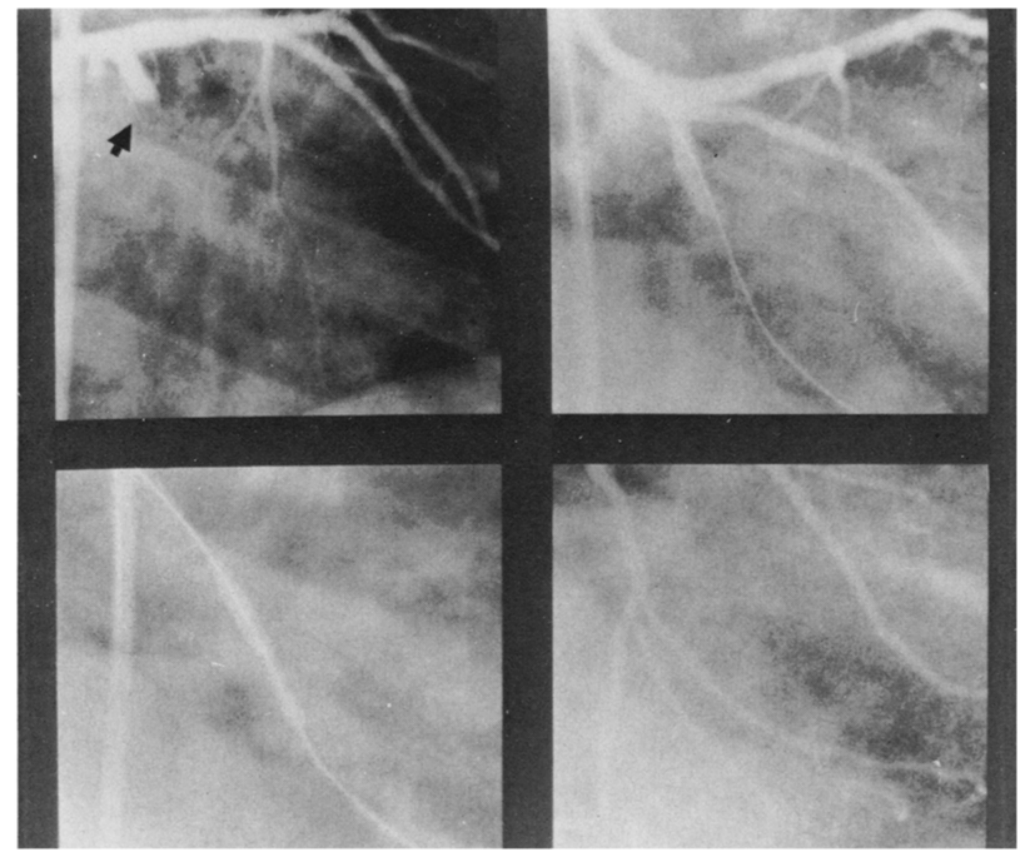

Fig. 1. Example of a vessel stump of the left circumflex coronary artery (upper panel, left). After perforation of the occlusion with the guidewire, the balloon catheter can be advanced across the lesion ( $u p p e r$ panel, right); the lesion is dilated (lower panel, left) with good angiographic results (lower panel, right).

coronary artery is even more important than with conventional lesions. If an approach with a standard soft-tipped guide wire fails, a stiffer guide wire may be useful. The guide wire should not be screwed into the occlusion because there is a risk of wire fracture, and it should be rotated no more than one revolution in either direction. Sometimes it is helpful to position a perfusion catheter in the vessel stump for better support of the guide wire. ${ }^{15}$ Specially designed guidewire delivery system ("hollow wire") for this particular purpose have been described, ${ }^{16}$ and information on more sophisticated systems, that employ tipped wires with high pushability ("magnum") or slow rotating wire systems will be available soon. After successful perforation, a dilatation with a small caliber low profile balloon catheter can be performed. Contrast media can be injected through the perfusion or the balloon catheter to visualize the vessel segment beyond the area of stenosis.

Newer techniques in cardiology, such as ultra-low profile balloon catheters, "balloon-on-a-wire" devices, direct laser energy, ${ }^{17}$ laser balloons, ${ }^{18}$ laser wires, ${ }^{19}$ slow rotational angioplasty systems, ${ }^{20}$ atherectomy catheters, ${ }^{21}$ abrasive tips, ${ }^{22,23}$ and thrombolytic regimens may improve the initial results of angioplasty of occluded vessels. Since angiographic techniques provide only limited information on the structure and consistency of a coronary vessel occlusion, intravascular imaging devices such as an-
Table III. Potential complications of PTCA of occluded vessels

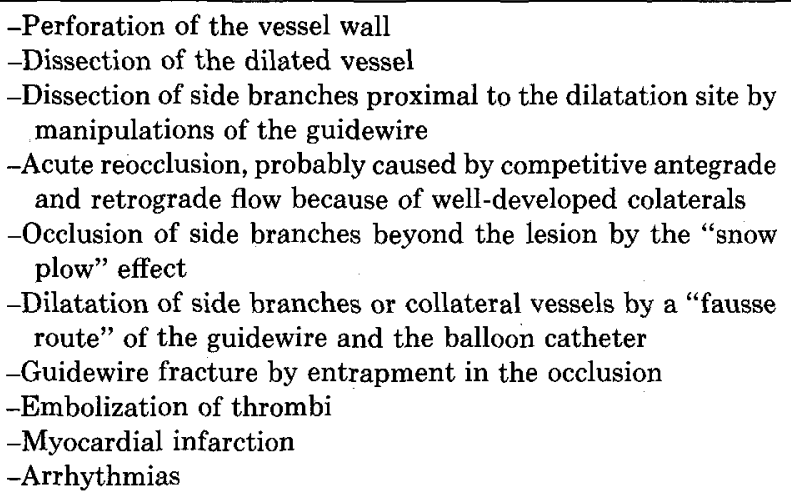

gioscopy and ultrasound are needed to delineate the intraluminal pathway as a guide for the recanalization devices and to prevent a "fausse route."

\section{COMPLICATIONS OF PTCA OF TOTAL OCCLUSIONS}

PTCA of a total occlusion is sometimes regarded as a low-risk procedure because preexisting $100 \%$ stenoses cannot become worse and because a well developed collateral circulation is present. The complications mentioned in Table III may also occur during angioplasty of conventional lesions, but some of them are likely to be more frequent in PTCA of total occlusions. A creatinine kinase elevation of more than 


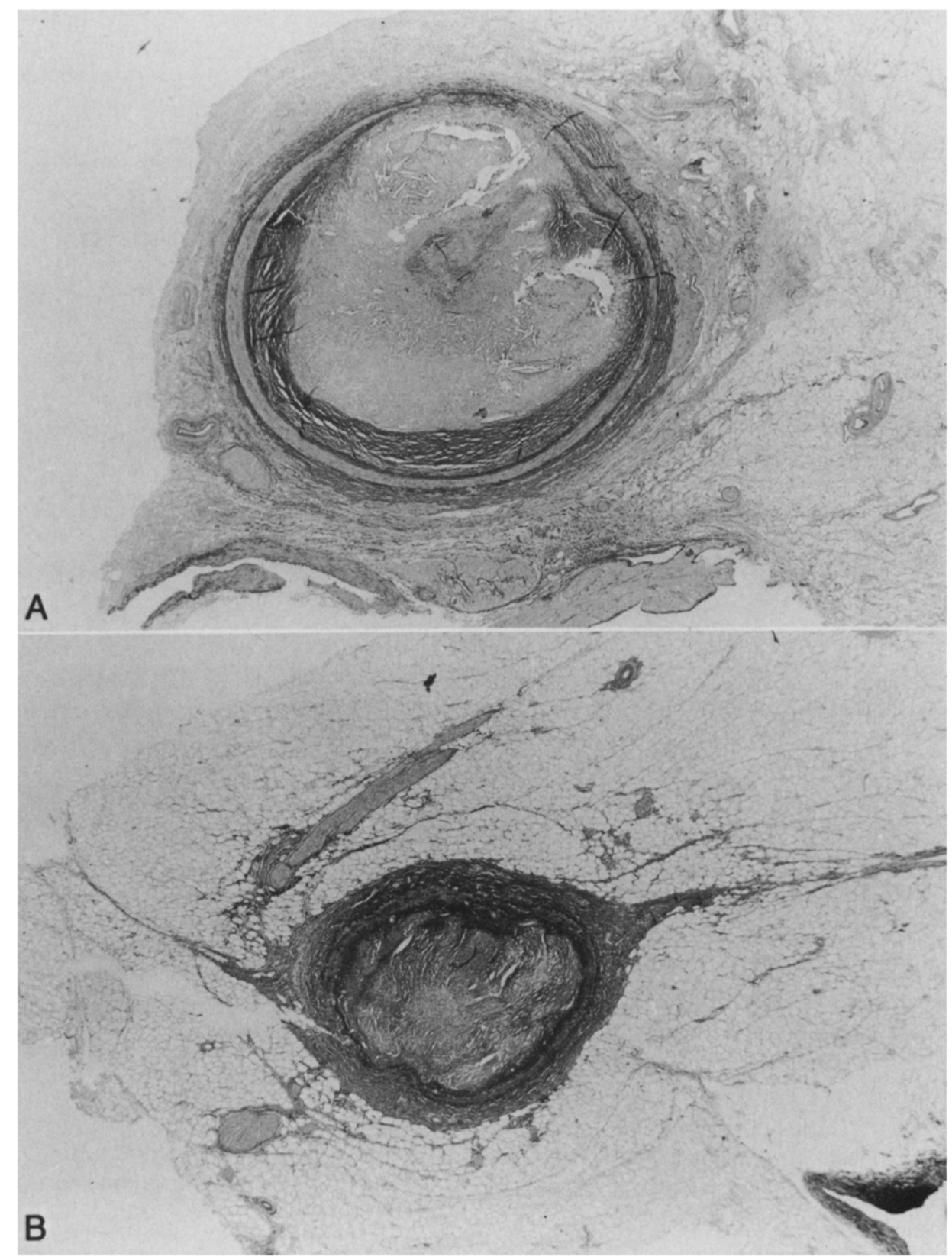

Fig. 2. Examples of the pathologic appearance of a chronic total coronary artery occlusion. A, The lumen is predominantly filled with atheroma and only marginal fibromuscular tissue. (H.A. stain). B, The lesion is mainly composed of fibromuscular tissue. (Elastic-van Gieson stain).

Table IV. Recurrence of angina pectoris after successful PTCA of occluded coronary arteries

\begin{tabular}{|c|c|c|c|}
\hline Authors (year) & $\begin{array}{c}\text { Follow-up } \\
\text { (months) }\end{array}$ & Patients & $A P$ \\
\hline Kereiakes et al. $(1985)^{6}$ & 7,3 & 40 & $10(25 \%)$ \\
\hline Safian et al. $(1985)^{24}$ & 16 & 47 & $21(45 \%)$ \\
\hline Clark et al. $(1985)^{26}$ & $\geq 6$ & 45 & $20(44 \%)$ \\
\hline Geuskens et al. $(1986)^{7}$ & $3-48$ & 46 & $15(33 \%)$ \\
\hline DiSciascio et al. $(1986)^{11}$ & $4-12$ & 29 & $14(48 \%)$ \\
\hline Melchior et al. $(1987)^{12}$ & $1-48$ & 49 & $14(29 \%)$ \\
\hline Totals & $\overline{1-48}$ & $\overline{256}$ & $\overline{94(37 \%)}$ \\
\hline
\end{tabular}

AP, Angina pectoris. twice the normal value occurs in $5.3 \%$ to $16.3 \%, 2,6-8$ a definite myocardial infarction in $1.1 \%$ to $2.5 \%{ }^{7,12,13}$ occlusion of distal vessels or side branches in $2.2 \%$ to $5.3 \%,{ }^{6,11}$ abrupt reocclusion in $5.3 \%$ to $7.7 \%, 6,10,24$ emergency coronary artery bypass grafting in $1.3 \%$ to $4.3 \%, 2,6-8,13,25$ guide-wire fracture in $0.6 \%,{ }^{13}$ rupture of the coronary artery in $1 \%(12)$, and significant arrhythmias (ventricular tachycardias, ventricular fibrillation, and symptomatic bradycardias that necessitate temporary pacing) in $2 \%$ (12) of the cases.

Most complications can be explained by coronary 


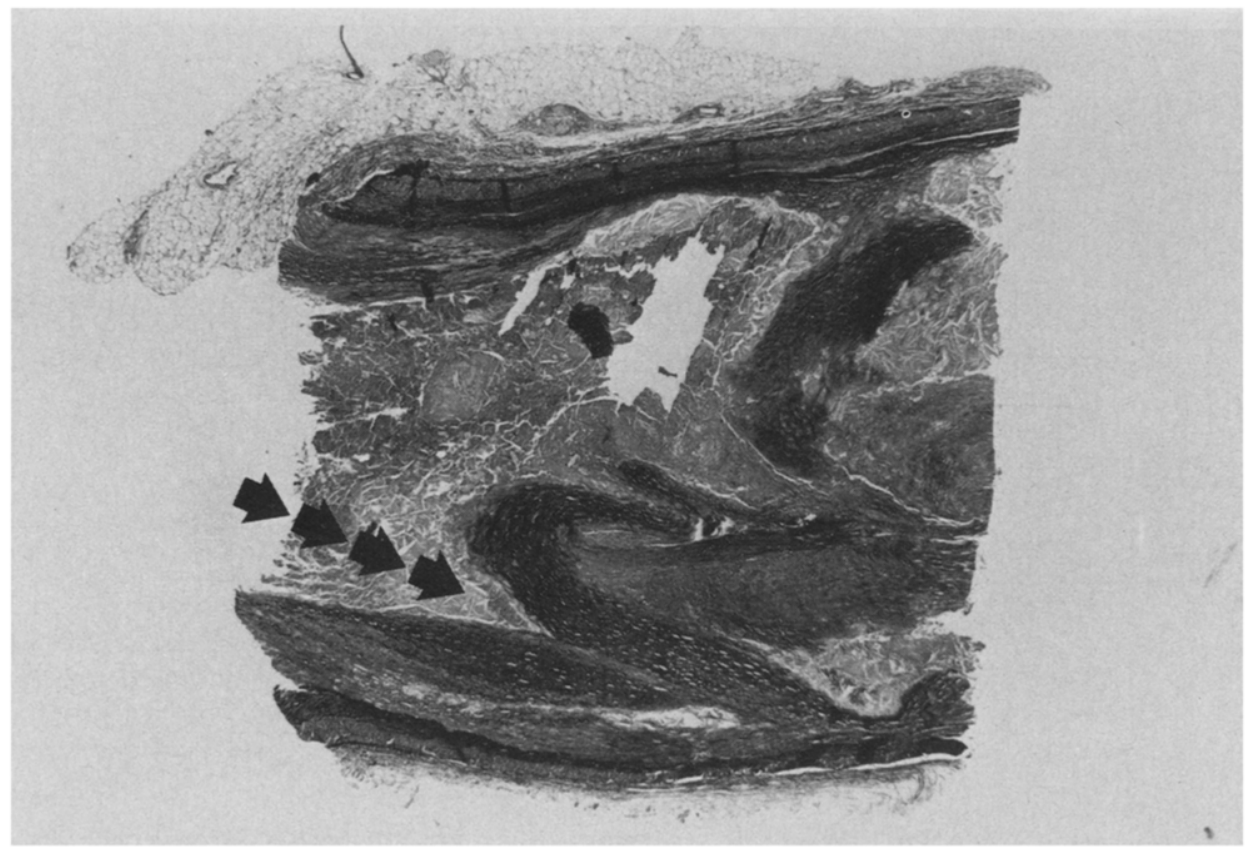

Fig. 3. Longitudinal histologic section through a totally occluded coronary artery showing atheroma and massive fibromuscular tissue; the arrows indicate a potential "fausse route" into the subintima if the lesion is negotiated by the guidewire in this direction (the filling defect is a fixation artefact.) (H.A. stain).

Table V. Restenosis after successful PTCA of occluded coronary arteries

\begin{tabular}{lccrr}
\hline Authors (year) & Follow-up (months) & Definition & Patients & Restenosis \\
\hline Holmes et al. $(1985)^{8}$ & 7 & $>40 \%$ increase & 10 & $2(20 \%)$ \\
Clark et al. (1985) & $\geq 6$ & $?$ & 45 & $25(56 \%)$ \\
Libow et al. $(1985)^{27}$ & 6 & $>50 \%$ loss & 42 & $18(43 \%)$ \\
Geuskens et al. $(1986)^{7}$ & $3-48$ & reocclusion & 32 & $9(28 \%)$ \\
DiSciascio et al. $(1986)^{11}$ & $4-12$ & $\geq 60 \%$ DS & 29 & $14(48 \%)$ \\
Melchior et al. $(1987)^{12}$ & $1-48$ & 40 & $22(55 \%)$
\end{tabular}

Definition, Definition of restenosis; increase, increase in percent of diameter stenosis; loss, loss in percent of initial gain of PTCA; DS, diameter of stenosis.

thrombus formation and/or dissection and embolization. There is no convincing evidence that angioplasty of total occlusions is more hazardous than angioplasty of conventional lesions. To reduce the risk of abrupt reocclusion after the procedure, full heparinization during at least 24 hours after PTCA is advised. Careful follow-up is mandatory and in the case of signs of restenosis (symptoms and/or noninvasive tests) coronary angiography should be performed. Our current practice is to perform angiographic follow-up within 2 to 3 months, and if restenosis is present, regardless of symptoms, repeat angioplasty is attempted during the same session. However, the merits of this approach have never been established.

Follow-up. The recurrence of angina pectoris and angiographic restenosis after successful PTCA of chronically occluded coronary arteries is presented in
Tables IV and V.* Angina pectoris recurs in $25 \%$ to $48 \%$ of the cases, which appears to be higher than after PTCA of conventional lesions. The reported incidence of restenosis depends on the completeness of the angiographic follow-up and also on the definition of restenosis. As there is considerable variation in the methodology adopted, the available studies are not very comparable. However, one may conclude that restenosis and reocclusion are more frequent findings after PTCA of occluded vessels than after PTCA of conventional stenoses. A study by Clark et $\mathrm{al}^{26}$ showed that restenosis was more frequent if lesions required more balloon inflations and higher inflation pressure. DiSciascio et al. ${ }^{11}$ found that restenosis appeared to be related to a higher degree of post-PTCA residual narrowing. Although angio-

${ }^{*}$ References $6-8,11,12,24,26,27$. 


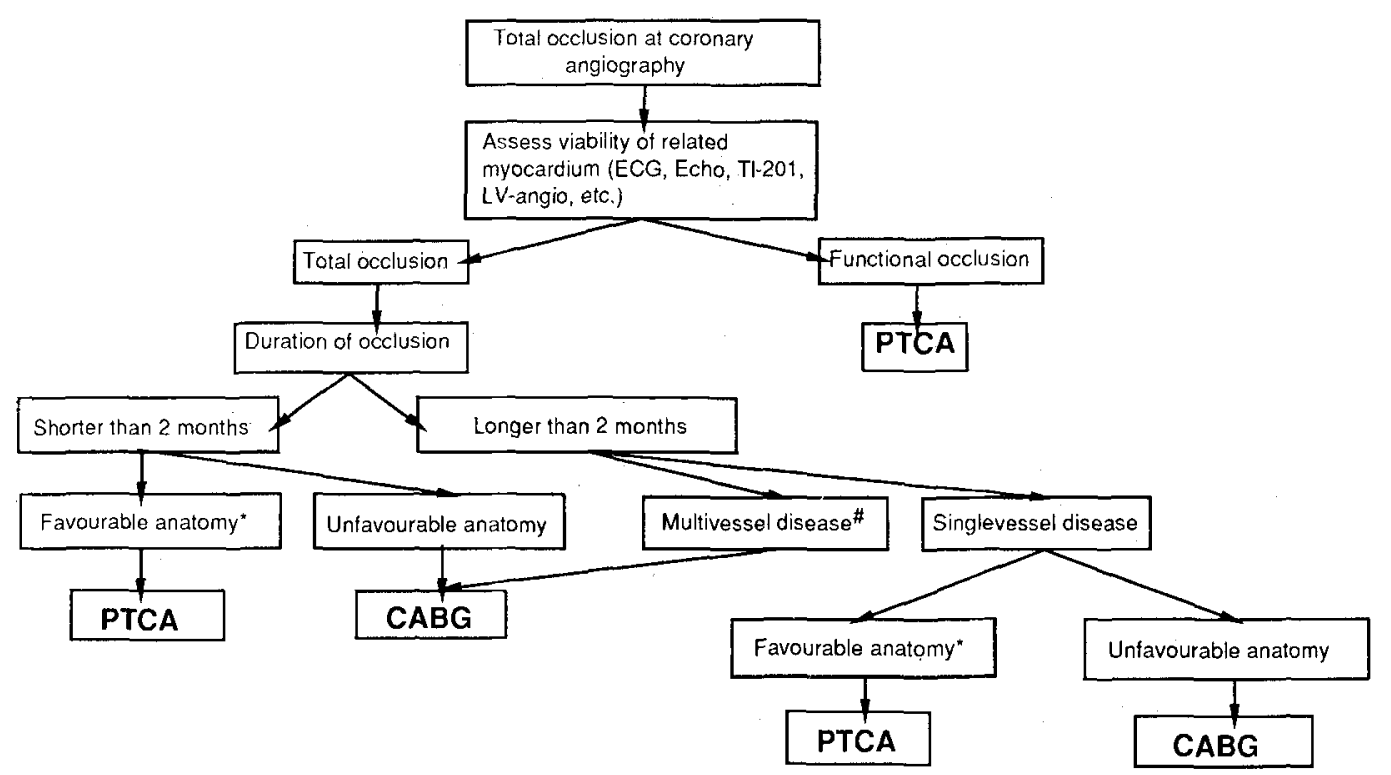

Fig. 4. Decision scheme for the approach to treatment of the patient with a chronic occluded coronary artery during coronary angiography. This scheme presumes anginal complaints in spite of optimal medical treatment. * Favorable anatomy consists of short length of occluded vessel segment, occlusion in a straight segment, good visualization of the segment beyond the occlusion by collaterals, the absence of stenoses distal to the occlusion, and the presence of a vessel stump. In particular in the presence of severe stenoses in a coronary artery that supply the myocardial region of the occluded vessel by collaterals (jeopardized collaterals). $E C G$, electrocardiography; $T I-201$, thallium 201 scintigraphy; $L V$-angio, left ventricular angiography.

graphically visible collaterals provide information on the course of the occluded vessel and thereby favorably influence the initial success rate of angioplasty, some authors have demonstrated that a well developed collateral circulation is associated with a higher restenosis rate. ${ }^{10,27}$ The degree of collateral supply is represented by the measured coronary wedge pressure, which is highest in the presence of chronic total occlusions. ${ }^{28}$ Therefore patients with high coronary wedge pressures, which is especially the case in vessels with a chronic total occlusion and a visible collateral supply, are at increased risk for restenosis. This could be explained by a decrease of transstenotic gradient, which might cause accelerated progression of stenosis severity at the dilatation site. ${ }^{29}$

With a large series of patients, Ellis et al. ${ }^{30}$ demonstrated that restenosis does not appear to reach the plateau phase at 6 months follow-up as is the case in PTCA of nonocclusive stenoses in which restenosis at the dilatation site occurs predominantly within the first 6 months after PTCA. ${ }^{31}$ Furthermore, it was shown that drug therapy with aspirin, dipyridamole, or warfarin did not influence the long-term results.
Whether restenosis and reocclusion can be reduced by additional techniques (e.g., laser balloon angioplasty or stenting) or alternative percutaneous techniques (e.g., high-speed rotational or direct laser angioplasty, whether or not in combination with pharmacologic regimens, remains to be established.

Conclusions. The initial success of PTCA of chronically occluded coronary arteries depends mainly on the duration of the occlusion and on several anatomic factors. The follow-up of these patients is characterized by a higher percentage of restenosis and recurrence of angina pectoris. Against this background, a strategy must be formulated for each patient with an occluded coronary artery and myocardial ischemia in the related flow region. In Fig. 4 a decision scheme for the approach to treatment of the patient with a chronic total occlusion is presented. This scheme presumes ischemia in the myocardial region supplied by the occluded vessel and angina pectoris in spite of optimal medical therapy. It is evident that no patient fits perfectly into such a scheme, which is no more than a basis for clinical management. Whether newer techniques in cardiology may improve the initial and long-term results of angioplasty of occluded vessels 
remains to be established by carefully designed prospective studies with angiographic follow-up in all patients.

\section{SUMMARY}

The occlusion of a coronary artery does not necessarily imply the existence of nonviable myocardium of that flow-dependent region, because the presence of a well developed collateral circulation may be a sufficient nutrient source. During an episode of increased demand for myocardial oxygen, this collateral blood supply may become insufficient, and symptoms of myocardial ischemia may arise. PTCA of the occluded vessel appears to be an attractive approach to relieve ischemia in this situation. The primary success of dilatation of totally occluded segments depends largely on the duration of the occlusion but also on anatomic factors such as total or functional occlusion, the length of the occluded segment, and good angiographic visualization of the coronary artery distal to the occlusion by collaterals. The primary success rate $( \pm 60 \%)$ of PTCA of occluded vessels is lower than the success rate $(>90 \%)$ of PTCA of nonocclusive stenoses. Also the restenosis rate $( \pm 40 \%)$ and subsequent recurrence rate of angina pectoris is higher, compared to the $30 \%$ restenosis rate after dilatation of conventional lesions. Newer percutaneous techniques such as lasers, newly designed guide wires, and intravascular imaging devices are necessary to increase the primary success rate. Whether these techniques will also improve the long-term results remains uncertain.

The authors thank R. J. van Suylen, clinical pathologist, for his expert help.

\section{REFERENCES}

1. Visser RF, vd Werf T, Ascoop CAPL, Bruschke AVG. The influence of anatomic evolution of coronary artery disease on left ventricular contraction: an angiographic follow-up study of 300 nonoperated patients. AM HEART J 1986;112:963-72.

2. Serruys PW, Umans V, Heyndrickx GR, et al. Elective PTCA of totally occluded coronary arteries not associated with acute myocardial infarction; short-term and long-term results. Eur Heart J 1985;6:2-12.

3. Kolibash AJ, Bush CA, Wepsic RA, Schroeder DP, Tetalman MR, Lewis RP. Coronary collateral vessels: spectrum of physiologic capabilities with respect to providing rest and stress myocardial perfusion, maintenance of left ventricular function and protection against infarction. Am J Cardiol 1985;50: 230-8.

4. Heyndrickx GR, Serruys PW, van den Brand M, Vandormael M, Reiber JHC. Transluminal angioplasty after mechanical recanalization in patients with chronic occlusion of coronary artery. Circulation 1982;66(suppl II):II-5.

5. Savage R, Hollman J, Gruentzig A, King S, Douglas J, Tankersley R. Can percutaneous transluminal coronary angioplasty be performed in patients with total occlusions? Circulation 1982;66(suppl II):II-330.
6. Kereiakes DJ, Selmon MR, McAuley BJ, McAuley DB, Sheehan DJ, Simpson JB. Angioplasty in total coronary artery occlusion: experience in 76 consecutive patients. J Am Coll Cardiol 1985;6:526-33.

7. Geuskens R, Umans V, Van den Brand M, et al. Electieve angioplastiek van totaal afgesloten coronairarteriën zonder acuut myocardinfarct: resultaten op korte en lange termijn. Ned Tijdschr Geneesk 1986;130:1185-90.

8. Holmes DR, Vlietstra RE, Reeder GS, et al. Angioplasty in total coronary artery occlusion. J Am Coll Cardiol 1984;3:845-9.

9. Grollier G, Commeau P, Foucault JP, Potier JC. Angioplasty of chronic totally occluded coronary arteries: usefulness of retrograde opacification of the distal part of the occluded vessel via the contralateral coronary artery. AM HEART J 1987; 114:1324-8.

10. Dervan JP, Baim DS, Cherniles J, Grossman W. Transluminal angioplasty of occluded coronary arteries: use of a movable guide wire system. Circulation 1983;68:776-84.

11. DiSciascio G, Vetrovec GW, Cowley MJ, Wolfgang TC. Early and late outcome of percutaneous transluminal coronary angioplasty for subacute and chronic total coronary occlusion. AM HEART J 1986;111:833-9.

12. Melchior JP, Meier B, Urban P, et al. Percutaneous transluminal coronary angioplasty for chronic total coronary arterial occlusion. Am J Cardiol 1987;59:535-8.

13. Safian RD, McCabe CH, Sipperly ME, McKay RG, Baim DS. Initial success and long-term follow-up of percutaneous transluminal coronary angioplasty in chronic total occlusions versus conventional stenoses. Am J Cardiol 1988;61:23G-28G.

14. Sanborn TA. Recanalization of arterial occlusions: pathologic basis and contributing factors. J Am Coll Cardiol 1989;13:155860.

15. De Swart JBRM, van Gelder LM, van der Krieken, El Gamal. A new technique for angioplasty of occluded coronary arteries and bypass grafts, not associated with acute myocardial infarction. Cathet Cardiovasc Diagn 1987;13:419-23.

16. Smith LDR, Katritsis D, Webb-Peploe MM. Use of a hollow wire to facilitate angioplasty of occluded vessels. Br Heart J 1989;61:326-30.

17. Foschi AE, Zapala CA. Direct argon laser irradiation of highgrade stenoses and total occlusions in native human coronary arteries and bypass grafts: initial clinical experience $[\mathrm{Ab}$ stract]. J Am Coll Cardiol 1988;13:60A.

18. Spears JR, Reyes V, Sinclair IN, et al. Percutaneous coronary laser balloon angioplasty: preliminary results of a multicenter trial [Abstract]. J Am Coll Cardiol 1989;13:61A.

19. Bowes RJ, Cumberland DC, Belli AM, et al. "Laser wire" for percutaneous angioplasty complete peripheral and coronary arterial occlusions-initial clinical results [Abstract]. J Am Coll Cardiol 1989;13:60A.

20. Kaltenbach M, Vallbracht C. Low speed rotational angioplasty for reopening of chronic coronary artery occlusionspreliminary results [Abstract]. Eur Heart J 1988;9(suppl A):56.

21. Pinkerton C, Simpson J, Selmon M, et al. Percutaneous coronary atherectomy: early experiences of multicenter trial [Abstract]. J Am Coll Cardiol 1989;13:108A.

22. Fourrier JL, Auth D, Lablanche JM, et al. Human percutaneous coronary rotational atherectomy: results and short term follow up [A bstract]. J Am Coll Cardiol 1989;13:228A:

23. Erbel R, Dietz U, Auth DC, et al. Percutaneous transluminal coronary rotablation during heart catheterization [Abstract]. J Am Coll Cardiol 1989;13:228A.

24. Safian RD, Snyder LD, Snyder BA, et al. Long term results and follow-up of coronary angioplasty of totally occluded coronary arteries [Abstract]. Circulation 1985;72:III-141.

25. Wexman MP, Clark DA, Murphy MC, et al. Patient selection, complications and predictors of success in PTCA of total occlusions [Abstract]. Circulation 1985;72:III-141.

26. Clark DA, Wexman MP, Murphy MC, et al. Factors predicting recurrence in patients who have had angioplasty (PTCA) 
of total occluded vessels [Abstract]. J Am Coll Cardiol 1986;7:20A.

27. Libow MA, Leimgruber PP, Roubin GS, Gruentzig AR. Restenosis after angioplasty (PTCA) in chronic total coronary artery occlusion [Abstract]. J Am Coll Cardiol 1985;5:445.

28. Probst P. "Collateral pressure" (occlusion pressure) during coronary angioplasty in coronary artery disease. In: Serruys PW, Meester GT, eds. Coronary angioplasty: a controlled model for ischemia. Dordrecht: Martinus Nijhoff, 1986:105-14.

29. Urban P, Meier B, Finci L, et al. Coronary wedge pressure: a predictor of restenosis after coronary balloon angioplasty. J Am Coll Cardiol 1987;10:504-9.

30. Ellis SG, Shaw RE, Gershony G, et al. Risk factors, time course and treatment effect for restenosis after successful percutaneous transluminal coronary angioplasty of chronic total occlusion. Am J Cardiol 1989;63:897-901.

31. Serruys PW, Luyten HE, Beatt KJ, et al. Incidence of restenosis after successful coronary angioplasty: a time-related phenomenon. Circulation 1988;77:361-71.

\title{
Frequency and significance of chamber collapses during cardiac tamponade
}

\author{
Boris Reydel, MD, and David H. Spodick, MD, DSc. Worcester, Mass.
}

Diagnosis of a tamponading pericardial effusion is often elusive, partly because cardiac tamponade is a continuum. Even clinically non-tamponading effusions are physiologically active; noninvasive studies in patients with small to large clinically nontamponading amounts of pericardial fluid showed definite physiologic effects that could only be due to increased ventricular interaction via increased coupling of the heart and pericardium by the fluid. ${ }^{1}$ Thus it is not surprising that the earliest description of chamber collapses by Shiina et al. $^{2}$ offered this finding as a sign of "impending" tamponade. Later, Engle et al. ${ }^{3}$ distinguished non-tamponading from tamponading pericardial effusions by M-mode echocardiography, showing persistence of posterior motion of the right ventricular endocardium beyond 0.05 second after mitral valve opening. Subsequently, right ventricular and right atrial chamber collapses were identified as diagnostic correlates of cardiac tamponade, occurring individually or in combinations and even in low pressure tamponade. ${ }^{4-7}$

Left atrial collapse is relatively uncommon, reported by Fast et al. ${ }^{6}$ in 5 of 39 patients, four of whom also had right atrial and ventricular collapse. Left ventricular collapse is reported rarely and as an iso-

From the Cardiology Division, Saint Vincent Hospital, and the Department of Medicine, University of Massachusetts Medical School.

Received for publication Nov. 24, 1989; accepted Jan. 2, 1990.

Reprint requests: D.H. Spodick, MD, Cardiology Division, Saint Vincent Hospital, Worcester, MA 01604.

4/1/19167 lated phenomenon in exceptional cases of postoperative effusion loculated over the left ventricle ${ }^{8}$ and in a nonloculated effusion in one patient with pulmonary hypertension and abnormal right cardiac chambers. $^{9}$

\section{METHODOLOGY}

We evaluated the frequency and reliability of right-sided cardiac chamber collapses in diagnosing cardiac tamponade, analyzing only reports of investigations including both a control population and patients in whom tamponade had been established by both hemodynamic and clinical criteria, as well as by meticulous M-mode and two-dimensional echocardiographic investigations (Table I). The methodology of each series was scrutinized for non-echographic criteria that would correspond to established diagnostic requirements ${ }^{10}$ including (1) hemodynamics showing virtual equalization of central diastolic pressures, (2) clinical observations of reduced arterial systolic pressures with (3) pulsus paradoxus, (4) jugular venous distension, and (5) improvement following pericardiocentesis. Thus these results were selected because the diagnosis and characterization of tamponade would satisfy the clinician and the hemodynamicist as well as the echocardiographer.

\section{OBSERVATIONS (Table I)}

Out of many careful descriptions and analyses of echocardiographic chamber collapses, four reports completely satisfied all requirements for both hemodynamic and clinical evidence. These series included 